\title{
Learning by Comparison: The Benefits of Co-Teaching for University Professors' Professional Development
}

\author{
Lyndsay R. Buckingham ${ }^{1 \dagger}$, Alfonso López-Hernández ${ }^{2 * t}$ and Birgit Strotmann ${ }^{3 \dagger}$ \\ ${ }^{1}$ Modern Languages Institute, Comillas Pontifical University, Madrid, Spain, ${ }^{2}$ Department of Education, Research Methods and \\ Assessment, Comillas Pontifical University, Madrid, Spain, ${ }^{3}$ Department of Translation, Interpreting and Multilingual \\ Communications, Comillas Pontifical University, Madrid, Spain
}

There is an abundance of studies that suggest that the use of co-teaching strategies in higher education courses can enhance instructors' professional development, mainly by providing a space for transfer of methodologies and tools, as well as critical reflection on one's teaching practice. However, little has been said about the actual processes through which co-teachers learn from each other. This study analyzes the opportunities of professional growth afforded to seven professors by eight co-taught courses, over two

OPEN ACCESS

Edited by:

Eline Vanassche, KU Leuven Kulak, Belgium

Reviewed by: Machteld Vandecandelaere, KU $\square$ Leuven, Belgium Jeongeun Kim, Arizona State University, United States

*Correspondence: Alfonso López-Hernández alhernandez@comillas.edu

tThese authors have contributed equally to this work and share first authorship

Specialty section: This article was submitted to Teacher Education, a section of the journal Frontiers in Education

Received: 28 September 2021 Accepted: 06 December 2021 Published: 22 December 2021

Citation: Buckingham LR, López-Hernández A and Strotmann B (2021) Learning by Comparison: The Benefits of CoTeaching for University Professors' Professional Development.

Front. Educ. 6:776991. doi: 10.3389/feduc.2021.776991 academic years, in the fields of Education and Translation and Interpreting. Specifically, it examines how professional relationships between co-teachers fuel teacher learning, the specific learning processes generated, and the areas of professional development impacted. To do so, 11 reflective teacher diaries were coded and analyzed, and further evidence was collected through focus groups interviews with students of some of the co-taught courses. Results suggest that comparison with the co-teacher is the main force behind participants' learning on co-teaching; furthermore, such comparisons enable three main learning processes: reflection, negotiation and transfer, bearing mainly on teaching methods and materials and use of technology. Finally, there is evidence that occasional or ongoing team teaching (two instructors simultaneously in class) can enhance the effectiveness of co-teacher comparisons.

Keywords: higher education, co-teaching, collaborative teaching, training methods, reflective teaching

\section{INTRODUCTION}

At a time when higher education programs are increasingly competence-based, instructors are expected go beyond a transmission model of education and promote student-centered methodologies and instructional practices. However, it is a fact that many-if not most-university professors have received little or no initial teacher training (Mas Torelló, 2011 ) and, on the other hand, in-service training is normally received on a voluntary basis. Ellis (2019) make reference to the knowledge and the qualification paradox as a key issue in quality assurance for universities, pointing out that institutions dedicated to the furthering of knowledge and acquisition of qualifications in their students at the same time pay little attention to knowledge and qualifications about teaching and learning in the staff that they hire. This might be the result of the prevalent focus of institutions on research production rather than quality of teaching, reflected in the criteria applied by national quality assurance agencies such as the ANECA in Spain (Strotmann and Custodio Espinar, 2021), and international 
rankings such as the Times Higher Education or the Shanghai ones, in which research production figures more prominently than teaching quality.

Of course, the outbreak of the COVID-19 pandemic resulted in a dramatic increase of in-service training provision at universities, focusing mainly-although not exclusively-on the effective use of ICT tools in order to support distance or hybrid learning. Still, there are serious doubts that traditional training in the form of seminars or workshops is the best format to advance university professors' professional development (Holland et al., 2018). More experiential formats like peer observation (Martínez Vargas et al., 2018; O’Leary and Savage, 2020; Ridge and Lavigne, 2020), lesson study (Lewis and Hurd, 2011; Murata and Lee, 2021) or co-teaching can provide an effective alternative or addition to current professional development programs in higher education.

The aim of this paper is to discuss how implementing coteaching strategies in higher education courses can serve to create a fruitful space for faculty professional development, mainly by enabling learning processes that will help professors develop their teaching and reflective competences. It is based on the experience of eight co-taught courses from two different degrees taught at a medium-sized private university in Madrid (Spain).

\subsection{What Is Co-Teaching?}

Co-teaching is the result of close collaboration between two or more instructors, who share responsibilities for a given group of students and subject(s). This partnership can take many forms, as seen here in the models described by Cook and Friend (1995).

- One teaching, one assisting. Both instructors are present in the classroom, but one takes a leading role while the other supports students and the leading instructor.

- Station teaching. Instructors divide course contents into more than one segment and teach their content to smaller groups as they rotate. Similarly, this type of coteaching may also take the form of two instructors rotating to teach different contents to the same group of students.

- Parallel teaching. Instructors divide the group of students according to certain criteria, and each teaches his or her group the same content that was previously planned by both educators.

- Alternative teaching. One instructor teaches the large group while the other leads a small group (typically 3-6 students) for the purpose of differentiation or to ensure personal attention.

- Team teaching. Both instructors are in the classroom with the entire group, and both lead the class while possibly alternating leading and supporting roles.

Co-teaching is relatively common in some countries in the form of partnerships between specialist and generalist teachers at the grade school levels to support recent immigrants or special education students (see Schwab et al., 2015 for an example). At the university level, co-teaching is gaining momentum more recently, particularly in initial teacher training degrees, resulting in partnerships between teacher trainees and in-service teachers (Murphy et al., 2015; Pettit, 2017; Turan and Bayar, 2017; Montgomery and Akerson, 2019; Simons et al., 2020) or between university professors as a model of collaboration (Bacharach et al., 2008; Ferguson and Wilson, 2011; Graziano and Navarrete, 2012; Ricci and Fingon, 2017; Custodio-Espinar et al., in press). In recent years, several studies published about experiences of co-teaching in other fields of study have also suggested positive outcomes (Blanchard, 2012; Lock et al., 2016; Carbone et al., 2017; Morelock et al., 2017; Holland et al., 2018; Lasagabaster et al., 2019; Peral Santamaría and Strotmann, 2019).

In contrast to countries such as Austria, Italy, and Mexico, the practice of co-teaching is rare in the context of Spain (OECD, 2020), despite the push by educational experts to adopt the technique due to its many proven benefits (see Lasagabaster et al., 2019). This might be due to the increased costs and difficulties associated with co-teaching and the important considerations that must be made before undertaking the challenge. It is generally agreed that co-teaching requires a significant investment of time and effort as well as professional training in order to be effective (Graziano and Navarrete, 2012; Ricci and Fingon, 2017). Instructors will also need to demonstrate trust, mutual respect, and accountability in a co-teaching partnership (Graziano and Navarrete, 2012). Finally, there are practical considerations such as the necessity to define classroom protocol and processes to avoid potential confusion and mistrust among students (Bacharach et al., 2008; Ferguson and Wilson, 2011; Graziano and Navarrete, 2012). However, these drawbacks are overwhelmingly offset by the potential benefits, suggesting that co-teaching is worth the effort.

\subsection{Professional Development Needs of University Professors}

In Europe, universities have recently experienced significant reforms in order to adapt to the European Higher Education Area (EHEA), what is commonly known as the "Bologna process." This has meant changes to degree study plans and the competences students are expected to develop, and therefore, to the role that educators are meant to play in the process. For example, Torra Bitlloch et al. (2012) suggest that university professors, in addition to transmitting their disciplinary knowledge, should create situations in which students are required to actively search for information, communicate their ideas to others, evaluate possible solutions to a problem and decide on the most appropriate actions. In essence, instructors should develop their pedagogical competence in order to ensure that students play an active role in their own learning process and learn to solve problems in a creative and collaborative way. This is consistent with the two types of learning suggested by O'Meara et al. (2017) to be essential to the continued professional development of faculty: scholarly learning, or that which develops their knowledge and skills related to their discipline, and teaching learning, that which allows them to improve as teachers. Mas Torelló (2011) suggests that, though university professors have extensive experience and knowledge related to their field of expertise, many came to the teaching profession with 
little to no pedagogical training. This is confirmed by the Trends report (2018) which states that only about half of higher educational institutions require teaching experience for professors (much less for other teaching staff), underlining the importance of developing these skills once at the university. However, according to the same source, only one-third of institutions require ongoing professional development for professors.

O'Meara et al. (2008) set the stage for the need for professional growth among university professors, pointing out the multifaceted aspect of the profession which involves striking a delicate balance between teaching students, making commitments to the community, engaging in rigorous and meaningful research, and finding satisfaction in their work. To this end, O'Meara and LaPointe Terosky (2010) suggest the following aspects as essential: learning (both scholarly and teaching), agency, professional relationships and commitment. The authors explain that these four aspects are both synergistic and mutually reinforcing, all contributing to job satisfaction and motivation. University professors have a need to continually learn in order to handle the challenges of the profession, including the use of new technologies, keeping up with developments in their field of expertise and responding to the needs of students. Agency involves taking an active role in shaping one's own career development in a purposeful way, which can be seen in the creation of a work-life balance or when pursuing research one considers to be important. Professional relationships have a significant positive impact on job satisfaction because they provide both personal and professional support and contribute to learning. Finally, faculty often make long-term commitments in order to contribute to society through research, social work or community education, and these commitments also sustain those who make them. There are personal forces that drive all four of these aspects of professional development, but the abovementioned authors insist that the institution should also promote them in order to support faculty and provide momentum. In return, institutions and students will logically benefit from a more satisfied and motivated teaching faculty.

In a similar framework, which is more focused on required knowledge, Mishra and Koehler (2006) assert that teachers should develop Technological Pedagogical Content Knowledge (TPACK), a combination of Technology knowledge (TK), Pedagogical knowledge (PK) and Content knowledge (CK). This division is quite similar to the dichotomy proposed by O'Meara et al. (2017) of scholarly knowledge and teaching knowledge (roughly equivalent to $\mathrm{CK}$ and $\mathrm{PK}$, respectively), but it further emphasizes the need for faculty to have specific training to face online instruction and teaching with technology (TK), made necessary by distance or hybrid learning. Indeed, the COVID-19 pandemic has recently thrust these training needs to the forefront, and many asked whether university professors were ready for the sudden change to distance, and later hybrid, learning. A survey of the available literature suggests that teachers worldwide were not psychologically prepared or sufficiently trained to face such a challenge due to lack of preparation resulting from reticence with technology (CaberoAlmenara and Llorente-Cejudo, 2020), difficulty in adapting instructional design to online learning (García-Peñalvo and Corell, 2020), lack of previous online teaching experience (Li et al., 2021), and frustration caused by the chaotic environment caused by the pandemic (Cameron-Standerford et al., 2020).

\subsection{How Co-Teaching Contributes to Professional Development}

According to the OECD, collaboration among teachers contributes to professional development as they learn from each other and consequently improve their own practices, leading to more innovative methodologies and benefitting students as a result (OECD, 2020). However, the same source makes a distinction between simple collaboration, including the negotiation of specific students' learning outcomes or sharing teaching materials, and a more interdependent form of collaboration, including peer observation and feedback, collaborative professional learning and co-teaching. The former is much more common than the latter, but those who practice more interdependent forms of collaboration report higher job satisfaction and higher self-efficacy (OECD, 2019). In a similar effort to compare degrees of collaborative teaching, Vangrieken et al. (2015) propose a continuum-based conceptualization of collaborative units based on the construct "team entitativity." According to this framework, co-teaching should lead to the creation of teaching teams with high levels of collaboration, where there is room for "deeper discussion on classroom practice" as well as making practical arrangements (Vangrieken et al., 2015, 35). Similarly, Laurillard (2012) proposes a conversational framework for teachers learning collaboratively, in which the interplay between the 1) teachers' own ideas and practice with 2) their students and 3) their peers features prominently, and which aligns well with co-teaching models.

While co-teaching cannot replace other professional development efforts, we would like to suggest that it can make a significant positive impact on teacher learning. In fact, research has pointed to teacher learning as one of the biggest benefits of coteaching among faculty. Through working closely together, mutual observation, and negotiating all aspects of the course, both experienced and novice professors learn from their experiences and from one another (Murphy et al., 2015). This learning is often focused on $\mathrm{PK}$, including developing and using new instructional strategies (Bacharach et al., 2008; Ferguson and Wilson, 2011) and becoming more reflective about their own teaching (Bacharach et al., 2008; Ferguson and Wilson, 2011; Kelly, 2018). However, studies also show that professors who coteach expand their subject or CK (Roth and Tobin, 2004; Bacharach et al., 2008), enhancing scholarly learning. We have not found any evidence to suggest that co-teaching may help develop TK.

To instructors initiating in the process, co-teaching may seem to limit their autonomy due to the need to negotiate the syllabus, share the classroom and/or class group, and communicate all aspects of the course. Considering that autonomy is essential to effective collaboration (OECD, 2020), this situation does not appear to be ideal. However, there is also evidence that co-teaching enhances instructor motivation due to the social aspect of the partnership (Ferguson and Wilson, 2011). 
Consequently, it is considered that instructors need both a sense of autonomy and social embeddedness in order to work effectively and be motivated (Kolleck, 2019). This mirrors the claims by O'Meara and LaPointe Terosky (2010) that all aspects of professional development should be developed by the individual but also supported by the institution and the collective.

Finally, co-teaching creates a need for self-reflection so that each instructor can learn what is necessary for successful collaboration and take these steps together (Lock et al., 2016). Indeed, Fuentes Medina and Herrero Sánchez (1999) found that the evaluation of faculty at the university level is often out of reach to the professors themselves. Therefore, self-evaluation would be a logical alternative which additionally encourages critical thinking, reflection and, therefore, professional development. Ross and Bruce (2007) make the same assertion, pointing out that self-evaluation has the advantage of allowing instructors to formulate their own goals, and colleagues and external change agents to directly influence teaching practice, ultimately resulting in increased teacher efficacy. O’Meara et al. (2017, 357) point out that scholarly learning is personal and that "the best examination of scholarly learning will include at least some measure of self-reporting." Certainly, self-reflection and self-evaluation allow the university professor to have direct control over their own professional development, and one effective tool for this practice is the reflective journal (Cowan and Westwood, 2006).

Based on the literature review conducted, and in light of the needs detected in the Trends (2018) report, as well as the demands placed on tertiary instruction by both the O'Meara and LaPointe Terosky (2010) framework and the TPACK model (Mishra and Koehler, 2006), the present study zooms in on the interplay between the professional relationship between co-teachers and the learning it generates, by analyzing what specific triggers, processes and applications are set in motion through reflective co-teaching. The focus of this paper is at the grassroots level and intentionally excludes all aspects relating to institutional support (agency, commitment).

\subsection{Research Questions}

In relation to the learning that results from the professional relationship between two co-teachers, the following three research questions were formulated:

- RQ1. How does the professional relationship between coteachers drive the learning process?

- RQ2. What specific types of learning processes does coteaching generate?

- RQ3. What professional areas do these learning processes impact?

This paper aims to answer these questions by highlighting challenges and affordances of co-teaching by means of an exploratory case study.

\section{METHODS AND MATERIALS}

A qualitative case study method following Baxter and Jack (2008) was selected for the study, to ensure in-depth exploration of the phenomenon of co-teaching while drawing from a variety of different sources, under a grounded constructivist paradigm as described by Charmaz (2017). Researchers believe that reality is co-constructed-in this case by participants in the study, including researchers-through an iterative process of data comparison and analysis, integrating emergent categories and codes and rechecking these against the data. This approach is in line with Philips and Zavros (2013) "democratic research method," which includes both participants' and researchers' points of view in the design of their study; Probst (2016) "direct experience of nondichotomized identity," where participant researchers relinquish authority in favor of mutuality; and Laurillard (2012) "design research," in which practitioners become co-researchers themselves.

The present study is the result of an internally funded teaching innovation project, which ran from 2018 to 2021 at a mediumsized private university in Madrid, Spain. It is a common institutional practice to split courses between two different professors, for a variety of reasons, such as facilitating scheduling, providing teaching in two different languages, or including professionals in the teaching. In some cases, the decision to assign more than one instructor to a given course is made top-down (e.g., by the head of department), and professors involved may display varying degrees of willingness to coordinate. For instance, in extreme cases, content, assessment and delivery are split in half, with little to no further communication between teachers until the end of the course, when an average grade between both halves of the course is calculated. Against this backdrop, a group of five professors involved in co-teaching decided to apply for funding to gather data on current practice, with the aim of improving the coteaching experience and using its innovative potential to the fullest. An additional two co-teachers were invited to participate, resulting in seven participants who formed different co-teaching partnerships, which were then documented by means of teacher diaries and student focus groups (as well as a series of other sources not essential to this paper), in order to ensure triangulation of data and the inclusion of multiple points of view. Data was gathered in both English and Spanish, allowing participants to choose which language they felt most comfortable with. All Spanish materials have been translated into English for the purpose of this article.

Diary research has been commonly used in second language learning contexts (Bailey, 1983; Bailey, 1990; Boud, 2001) and found to provide insights into learning/teaching processes, instructor beliefs, decision-making processes, feedback strategies, or classroom techniques. Despite their subjectivity, these diaries offer the advantage of reflecting development over time (Mackey and Gass, 2016), which is why teacher diaries were chosen as the main tool for researchers to explore the challenges and affordances of co-teaching for professional development. All teaching partners committed to writing a weekly journal entry about their co-teaching experience, which was complemented by semi-structured student focus group interviews to obtain information on student perceptions of the co-teaching experience. Table 1 provides an overview of participants, courses and materials. 
TABLE 1 | Courses included in the study.

\begin{tabular}{|c|c|c|c|c|c|c|}
\hline Course & Undergraduate degree & $\begin{array}{c}\text { Year } \\
\text { of } \\
\text { study }\end{array}$ & $\begin{array}{l}\text { Professor } \\
\text { code }\end{array}$ & $\begin{array}{l}\text { Course } \\
\text { code }\end{array}$ & $\begin{array}{l}\text { Co-teaching } \\
\text { model }\end{array}$ & $\begin{array}{c}\text { Year of } \\
\text { co-teaching } \\
\text { experience }\end{array}$ \\
\hline History and Literature of the English-Speaking Countries & Translation and Interpreting & 2 & $F, D$ & C6 & Station & 4 \\
\hline Written Communication Skills & Translation and Interpreting & 1 & $E, D$ & C3B & Station & 3 \\
\hline Written Communication Skills & Translation and Interpreting & 1 & $E, D$ & $\mathrm{C} 3 \mathrm{C}$ & Station & 2 \\
\hline Oral Communication Skills & Translation and Interpreting & 1 & $E, D$ & $\mathrm{C} 4 \mathrm{~B}$ & Station & 1 \\
\hline Teaching English as a Foreign Language ॥ (TEFL ॥) & Primary Education & 4 & $A, B$ & C5 & Station & 2 \\
\hline Teaching English as a Foreign Language II (TEFL II) & Infant Education & 4 & $G, B$ & $\mathrm{C} 7$ & Station & 1 \\
\hline Content and Language Integrated learning (CLIL) & Primary Education & 4 & $\mathrm{~B}, \mathrm{C}$ & C1 & Team & 3 \\
\hline Content and Language Integrated learning (CLIL) & Infant Education & 4 & $A, C$ & $\mathrm{C} 2$ & Team & 3 \\
\hline
\end{tabular}

The fact that researchers were also participants in the study might initially be considered a drawback due to issues of subjectivity; however, this design provided a series of advantages regarding 1) in-depth, first-hand knowledge of the reality of co-teaching, 2) immediate application of good practice detected in posterior teaching and 3) constant food for constructive discussion. This design is in line with Jasper (2005, 249), who comments on the advantages of a self-critical use of researchers' own reflective writing as "a method in itself" and Stynes et al. $(2018,156)$ description of the potential of the researchers' own "reflection-on-action," arguing in favor of "reflexivity" as part of the research process and against "the incorrect assumption that researchers must erase themselves from qualitative research processes." Similarly, Laurillard $(2012,6)$ maintains that "principled reflective practice" in design research can provide a feedback loop on the effectiveness of teaching, to be carried out by the teacher as co-participant rather than the researcher/experimenter. Triangulation of diary data with student focus group output provided an additional safeguard against covert subjective bias. Researchers ensured student anonymity in focus groups by never interviewing their own groups. All participants were informed that involvement in the study was voluntary, and data would be anonymized before publication; a consent form was provided and signed before including any information.

Regarding the diaries, professors were instructed to make weekly entries and provided with a semi-structured template including course/faculty identification data and a request to reflect upon the following points:

(1) Joint planning (content, assignments, assessment, meetings...)

(2) Teaching strategies and lesson delivery (tasks, materials, perceptions, and feelings of teacher and/or students...)

(3) Teacher interaction inside and outside of class (channels of communication, frequency of communication, concerns...)

(4) Reflections on future changes, challenges, achievements...

(5) Any other issue they considered relevant

Questions (1) and (2) refer to standard elements of teacher training, while question (3) is specific to the co-teaching situation. The concern with planning, communication, delivery and assessment is reflected in co-teaching research (e.g., Bacharach et al., 2008; Graziano and Navarrete, 2012; or Montgomery and
Akerson, 2019). Questions (4) and (5) provide a space for participants to add their own concerns and perceptions. Question 4 encourages co-teachers to reflect on the design as compared to the outcome of the learning experience, both for themselves and for their students, to improve practice (Laurillard, 2012, 8-9). All questions were framed is such a way as to avoid bias regarding co-teaching.

In year two of the project, in addition to teacher diaries, student focus groups were formed by contacting student representatives, usually after the end of the semester and after publication of final grades. Student representatives were asked to find three to five volunteers among their classmates who would be willing to participate in a group interview, to be conducted either on campus or online (see Table 2).

Interviewers were provided with brief procedural instructions, a list of general interview questions and a series of prompts in case additional information needed to be elicited:

(1) What were the positive aspects of having two professors in this course?

(2) What were the drawbacks of being taught by two professors?

(3) How did the COVID-19 pandemic affect your course? (Do you think having two professors has helped overcome problems or enhanced them?)

(4) What aspects of the co-teaching experience could be improved?

(5) Is there anything that you would like to add?

Interviews were recorded and students were asked to give written consent to this procedure. Recordings were then transcribed, anonymizing the different speakers.

Data from diaries and interview transcriptions were collated in NVivo, a qualitative data analysis software. In line with Saldaña (2021), instructions and interviewer utterances have not been coded, and three different cycles of coding have been run to 1) ensure intercoder reliability, 2) obtain an initial set of categories and codes agreed on by all coders and 3) confirm whether the codes were equally applicable to the different sources (diaries, focus groups). Initial coding was carried out inductively, in line with grounded theory, to obtain a preliminary list of codes from the analysis of four initial diaries; codes were then compared, filtered, and categorized. The second and third rounds of coding were carried out deductively, applying the initial list of codes to all available diaries (11) and focus group transcriptions, thus using a 
TABLE 2 | Student focus groups.

\begin{tabular}{|c|c|c|c|c|c|c|}
\hline $\begin{array}{l}\text { Focus } \\
\text { group }\end{array}$ & $\begin{array}{l}\text { Group } \\
\text { code }\end{array}$ & Course & $\begin{array}{l}\text { Year } \\
\text { of } \\
\text { study }\end{array}$ & $\begin{array}{l}\text { Professor } \\
\text { code }\end{array}$ & $\begin{array}{l}\text { Co-teaching } \\
\text { model }\end{array}$ & $\begin{array}{c}\text { No of } \\
\text { participants }\end{array}$ \\
\hline 1 & $\mathrm{C} 3 \mathrm{C}$ & Written Communication Skills & 1 & $E, D$ & Station & 8 participants (students $A, B, C, D, E, F, G, H$ ) \\
\hline 2 & C5 & TEFL ॥ & 4 & $A, B$ & Station & 5 participants (students A, B, C, D, E) \\
\hline 3 & C6 & History and Literature of the English-Speaking Countries & 2 & $F, D$ & Station & 3 participants (students A, B, C) \\
\hline 4 & $\mathrm{C} 7$ & TEFL ॥ & 4 & $\mathrm{G}, \mathrm{B}$ & Station & 4 participants (students A, B, C, D) \\
\hline
\end{tabular}
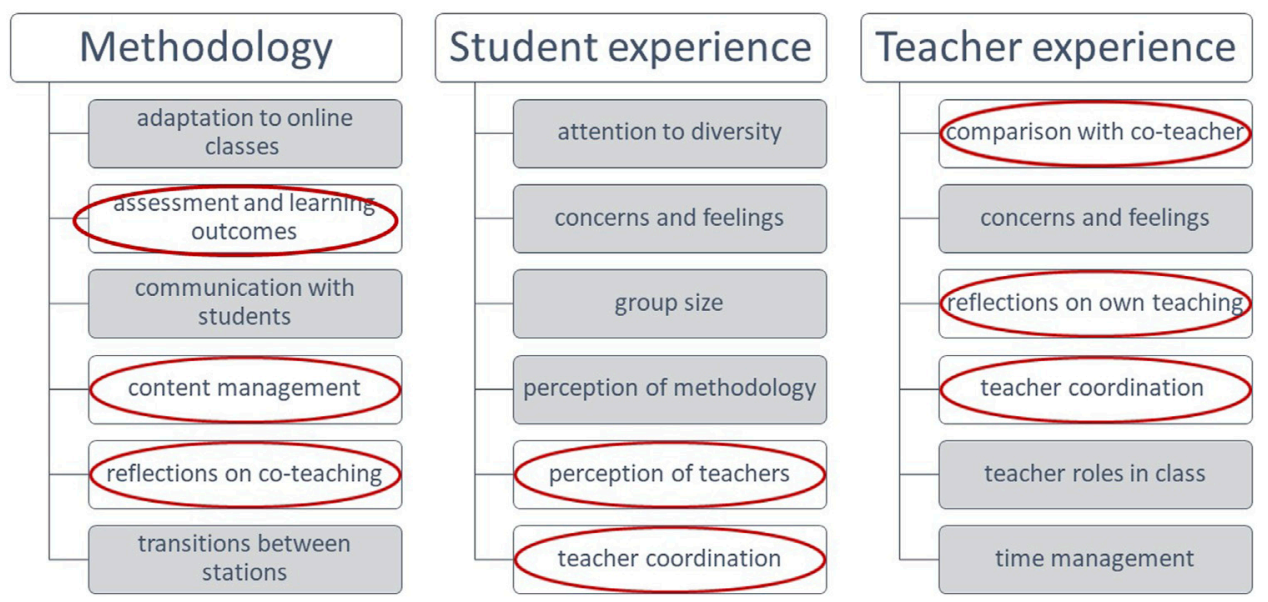

FIGURE 1 | Project categories and codes.

procedural (Friedman, 2012) or cyclical data analysis process (Watson-Gegeo, 1997, in Mackey and Gass, 2016) to reach a hypothesis. After discussion among coders, categories and codes were adjusted, a project codebook created, and a final list of categories and codes established.

For the present paper, researchers pre-selected those codes that promised to provide the richest results, both according to the literature and their own experience during the time of the innovation project. Figure $\mathbf{1}$ shows all categories and codes used in the study; codes analyzed for the present paper are circled in red. Professors' experience as reflected in their diaries was used as the main source of information and then complemented with student focus group comments to corroborate whether both perspectives coincided. In the results section, information is presented in three main blocks, corresponding to the research questions posed: The impact of the professional partnership on participants' learning processes (RQ1), the resulting learning processes (RQ2) and the actual application of the results of these processes to key teaching areas (RQ3).

Participants' voices will be included in the narrative by means of salient quotes, using the identifiers outlined in Tables 1, 2. For instance, a teacher diary entry related to the first course, History and Literature of the English-Speaking Countries, would be identified as "C6, PF" for "Course 6, Professor F," while a student comment during the focus group discussion about the same course might be identified as "C6, SA" (Course 6, Student
A). Due to the amount of material available, the authors have been forced to be selective regarding quotes in their narrative but have taken special care to always represent multiple perspectives, particularly in cases of disagreement among participants.

Regarding quantitative analyses included in the results, these were also carried out in NVivo, for the purpose of identifying prevalent issues by means of either 1) an analysis of coverage, i.e., what percentage of the total or partial text analyzed is dedicated to a given code (see Table 3) or 2) a word frequency count in the text entries relating to the codes preselected for the current study (see Figure 2). All quantitative data is used descriptively only, to provide supporting evidence for emerging themes.

\section{RESULTS}

To gain initial insight into the extent to which the data supports the hypothesis that co-teaching is beneficial for faculty professional development, word frequency and text coverage analyses were run in NVivo. Figure 2 is a word cloud based on the text of all the teacher diaries included in the study. Only words of four letters or more were included, and grammatical words, teacher names, and common words with little significance (i.e., students, class, teacher, teach) were omitted in order to have a meaningful analysis. The relative size of the word reflects the frequency with which it appears. 
TABLE 3 | Frequency of appearance and average coverage of main topics.

\begin{tabular}{|c|c|c|c|c|}
\hline Topics & Frequency (diaries) & $\begin{array}{c}\text { Average coverage (diaries) } \\
(\%)\end{array}$ & Frequency (focus groups) & $\begin{array}{c}\text { Average coverage (focus } \\
\text { groups) }(\%)\end{array}$ \\
\hline Teacher coordination & 255 & 37.49 & 60 & 22.37 \\
\hline Assessment & 119 & 16.76 & 79 & 24.71 \\
\hline Comparison with co-teacher & 107 & 15.19 & 56 & 13.92 \\
\hline Content management & 93 & 17.85 & 41 & 20.79 \\
\hline Reflection on own teaching & 89 & 15.11 & 0 & 0 \\
\hline Reflection on co-teaching & 85 & 13.42 & 43 & 17.06 \\
\hline Perception of teachers (individually) & 13 & 0 & 43 & 13.93 \\
\hline
\end{tabular}

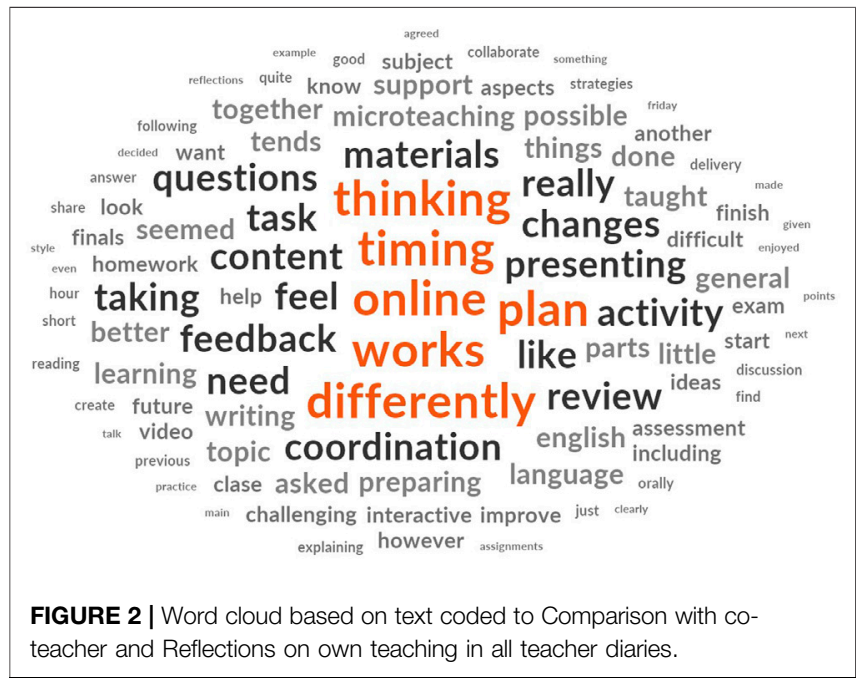

This word cloud shows an emphasis on reflection in the diaries with words like thinking, feel, and like. The central appearance of the word online demonstrates the importance of the change to online teaching in this period of time. Words such as plan, content, presenting, and coordination reflect the importance of content planning and coordination between coteachers. There was also a need for negotiation of specific classroom methodology, seen in words like feedback, review, activity, questions, task, and materials. The words differently, need, and changes imply transfer of learning outcomes by means of a repetition of the experience and desire for improvement.

Table 3 shows the codes selected for analysis (see Figure 1) that reflect the research questions and their appearance in the teacher diaries and student focus groups. Frequency refers to the number of times any amount of text was coded to the topic, either in the diaries or in the focus group transcripts. Average coverage was calculated by taking the percentage of coverage in which the code appeared in each file (whether diary or transcript) and calculating the average between all of them. Although relative length of excerpts does not always directly imply relative importance, these numbers may offer some insight into the comparative significance of each topic for each group, professors and students.

What follows is a presentation of the results of the analysis of the codes elucidating how the professional relationship between co-teachers sets a series of learning processes in motion and what teaching areas are affected by these processes (Figure 3).

\subsection{The Professional Relationship: Learning by Comparison (RQ1)}

As seen in Table 3, instructors wrote a considerable amount of text making explicit comparisons between themselves and their co-teachers; additionally, many comments were implicitly comparative, in noting differences, describing negotiation processes, and outlining actual implementation strategies. For example:

C3B, PD: The other issue I am worried about is teaching styles. Last year the group perceived me as more "academic" and possibly, as a result, more "difficult." I want to change that perception this year and am making slide in my Powerpoints simpler and eliminating content that is too theoretical. Let's see how that works out.

The comparisons between co-teachers that emerged mainly focused on methodology both in class and online, evaluation and feedback, the use of teaching materials, and to a lesser extent, the use of technology. There was some comparison in terms of content knowledge, generally focusing on the complementarity between professors. These comparisons appeared in the teacher diaries, and students compared their professors occasionally in the focus groups. In the diaries, much of what was written refers to concerns about differences between co-teachers as perceived by students, whether in relation to materials or methodology, while students mentioned differences between professors both positively and negatively.

\subsection{Learning Processes (RQ2)}

The comparison triggered by the co-teaching situation generated a learning process that is based on three key strategies: 1) deep reflection on each instructor's own teaching as compared to their partner's, 2) negotiation between partners to find optimal resources and methodologies to fulfill course objectives and 3) an actual transfer of methodologies between both partners. Moreover, reflection, negotiation and transfer occurred both in isolation and in combination. Participants applied these processes to three main areas of concern: teaching methods, materials and use of technology (the latter as a result of the impact of the 

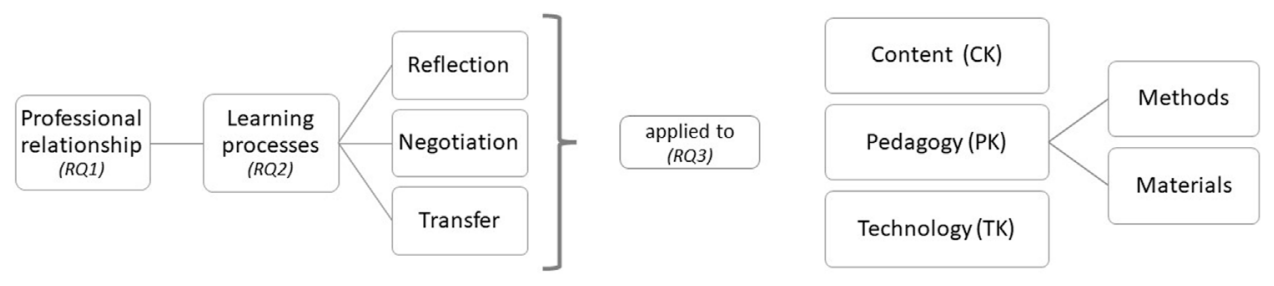

FIGURE 3 | Results by research question.

COVID-19 pandemic and resulting switch to online and hybrid teaching models).

\subsubsection{Reflections}

During their reflections, professors became aware of differences between their own and their partners' teaching styles. Indeed, almost all the participating professors made comments to compare their own teaching styles to those of their coteachers. Some of these reflections came about due to their own perceptions of student opinion.

C3B, PE: It seems that [Prof D] seemed more academic to them and I seemed more focused on professional aspects. I think that this perception comes from the fact that the students already know me from first semester, as I taught them the Theory and Practice of Translation at the beginning of the year and they know that outside of the university I work as a professional translator. For this reason, I think that their perception is biased and probably misguided. In any case, I may have to make an effort to appear more academic this year.

C7, PB: [...] I get the feeling that [Prof G] is stronger than I am when it comes to guiding students in the use of resources and materials. [...] On the other hand, I perceive my strengths to be being very analytic as well as really insisting that students integrate the theory and the strategies that I present or demo in the microteachings. Also, I think that my strategy of having plenary feedback after all the microteachings on a given session is especially powerful.

Others were based on their own perceptions and illustrated complementary strengths between co-teachers. For instance, one participant also reflected on differences based on more personal characteristics as a result of the time he spent with his co-teacher in the classroom.

C3B, PE: When we did the interviews, I felt somewhat nervous, and I don't know if it is because of the presence of [Prof D] or because we were recording the interviews (I don't like recording myself at all). Partly, it made me feel somewhat judged, but in the middle of the first interview the feeling subsided and I felt more relaxed. Afterwards, when [Prof D] directed the interviews in English, it impressed me how well prepared she was. She always seems very professional to me (much more than myself. ..)

The process of using and adapting each other's materials also gave rise to critical reflection on one's own teaching aids and strategies.

C5, PA: One thing I've noticed is that we tend to take each other's materials and make them our own, or modify them slightly for the group we're teaching. In fact, [Prof B] took one of my presentations and later told me that he had switched around some of the contents in order to make connections that I hadn't done before. I found this really useful because after teaching the same content a few times, I tend to organize it and teach it in the same way. But this forced me to look at it in a different light and notice that it could be interesting to teach some contents in a different order to highlight the connection between certain topics. I don't know whether I'll make the change in the future or not, but I like that sharing my materials with another teacher helps me to reflect on how I've planned my classes and how they could be improved.

Another reflection considered the difficulties caused by differences in the pace taken when planning.

C6, PD: I find it a little bit stressful that [Prof F] and I $[\ldots]$ have a different rhythm of doing this. I usually try to plan very far ahead: I like everything, if possible, to be done even before the holidays and [Prof F] is a little bit more last minute. His priorities are different, which is logical because he's a part time teacher and I'm a fulltime teacher.

Regardless of the stimulus that caused the reflection, participating faculty contemplated their own teaching often, suggesting that co-teaching and the writing of a diary contribute to professional development in the form of reflective teaching.

\subsubsection{Negotiation}

Planning and teaching a course with another instructor requires constant coordination and negotiation before, during and after 
the actual teaching period. This became very prevalent in the diaries when, within a week's time, professors had to change from campus-based to online teaching in March 2020.

C2, PA: There was discussion among the teaching team whether shorter classes and more online work was better than longer classes. Some felt that shorter Collaborate classes were better to avoid fatigue with having to pay attention for so long, while others felt that longer Collaborate classes were better in order to offer more support to students while they worked through tasks. We ended up continuing with classes that were approximately the same length as classroom classes ( $1 \mathrm{~h}, 40 \mathrm{~min})$ and assigning some videos and tasks outside of class.

This extract shows potential conflict, but in fact was resolved after negotiation between the three teachers, who reached an agreement regarding the length of online classes. With respect to negotiation, professors sometimes expressed concern about differences of opinion and not all issues were resolved. However, all diary entries expressed respect for the other's point of view and a genuine desire to find the best solution for the students in class.

\subsubsection{Transfer}

In many cases, reflection and/or negotiation would then lead to an actual transfer of methodological aspects to one's own teaching. Below are two examples of such a transfer taking place, related to teaching methodology, including assessment.

C5, PA: I got the idea of asking students to prepare short demos from [Prof B] in previous years, and this is the first year I'm making continued use of it. I really see the benefit of having them prepare the activities...

C6, PF: We discussed what should be done when students give an oral presentation remotely and it is clear that they are reading material that is not their own. [Prof D] came up with a good solution for marking the students down in such cases.

Participating professors clearly resorted to all three strategies in a variety of contexts, but mostly focusing on methods, materials, and technology. In what follows, the application of the learning processes to these three main areas of activity will be demonstrated.

\subsection{Professional Areas Affected}

When analyzing the material in the diaries, three general topics emerged: teaching methodology, teaching materials and use of technology. Each of these is described below in turn, and content knowledge has been included in order to respond to the chosen professional development frameworks (Mishra and Koehler, 2006; O’Meara and LaPointe Terosky, 2010).

\subsubsection{Content Knowledge}

Only one participant mentioned learning content from another professor, and it was related to content that she had not taught previously.
C6, PD: [...] one of the wonderful things in this coteaching experience is that [Prof F] has taught everything so he's very flexible with regard to taking on any of the content that I don't manage to put into my class; hopefully in the future I will get to the same level of knowledge of the material-right now I feel that I still lack more profound knowledge of certain aspects, though I have taught maybe $2 / 3$ of the class by now.

Students also noticed the specializations of each instructor in station teaching environments, noting in two classes (C5 and C6) that the two professors complemented each other by each focusing on teaching within their expertise.

\subsubsection{Teaching Methodology}

Professors often mentioned a concerted effort to unify methodologies in an attempt to show a united and coordinated front to students. As part of this effort, most teaching partners preferred to teach at least one class together, usually at the beginning of the semester.

C3B, PD: In general, I feel that having both teachers in the classroom from time to time is an added benefit and should be contemplated as a set part of the course.

\subsubsection{Differences in Methodology}

In their diaries, professors described differences in methodologies in both a positive and negative light. First, in the negative sense, they cited some disagreements on issues that they considered should be coordinated. For example, in Classes 1, 2 and 3B there were disagreements in the way that online classes were taught when first switching to distance learning due to the COVID-19 pandemic.

C3B, PD: [Prof E] and I spoke about how to deliver our classes online and initially, it seemed to me that [Prof E] preferred asynchronous delivery, i.e., making materials available and giving feedback in writing. My personal preference is different. From my experience in online teaching, I have found that permanent contact is very important, and opportunities for synchronous interaction contribute to class cohesion. I am a bit worried about how students will react to a different methodology from each of us, in a situation that is already made complex due to the change to online teaching.

However, there were also mentions of the positive aspect of a difference in methodologies by both professors in their diaries and the students in the focus groups.

C7, SC: As each teacher has their own way of teaching, in the end, that's OK, because maybe if one teacher doesn't convince you, then ... I mean, you have two ways in which to learn, so, it's not only that each of them is specialized in certain contents, but each of them is also teaching you in their own way. So you learn different things in different ways. 
C2, PB: I feel that students benefit from the variety of instructional strategies and materials in each coteacher's module design-and there's three of us! For instance, I feel that [Prof C] and [Prof A] are stronger at incorporating theory than I am. In turn, each of them has their own style when doing it.

One professor expressed the desire to observe both her coteachers in order to know more about their methodologies and communication styles without suggesting that a difference with her own would be necessarily negative.

C3B, PD: I would very much like to observe one of [Prof E]'s classes, to see how he delivers his lessons, which I feel are probably much more holistic and open. In any case, I think we need to strengthen our narrative linking our sessions into one coherent learning process.

Whether positively or negatively perceived, differences in methodology were a source of potential conflict and required communication between teaching partners to resolve disagreement, for example concerning video recording classes or reducing live class time for online session. However, teacher diaries reflected mostly successful negotiations or adaptations among co-teachers, with the result that students did not perceive the latent conflict potential.

\subsubsection{Evaluation and Feedback}

The diaries also reflected a significant transfer of both formative and summative assessment strategies and tools between teachers.

C5, PA: We switched groups this week, and [Prof B] had the idea of starting the first class with a short review of the previous block.

C1, PB: Another area of disagreement was how to adapt our usual exams to the online setting. Whereas I initially vouched for maintaining the usual structure, maybe shortening length a bit, we finally agreed on a simplified structure.

Moreover, participating professors also identified the complementarity of instructor feedback to students as one of the main strengths of co-teaching, as seen above. Some students also found this to be an advantage of having two instructors.

C7, SD: When we turned in our portfolios, both professors corrected it. And this seems positive to me, because you don't only get what just one of the professors sees in your work, but you get what they both see, and in the end you have a more complete evaluation.

In some cases, this benefit was not necessarily obvious to the students, and had to be explained:

$\mathrm{C} 3 \mathrm{~B}, \mathrm{PD}$ : One issue that has come up is the fact that as a translation teacher assessing the use of students' L1, [Prof E] tends to take off far more points for errors in orthography and punctuation than I do as a language teacher. As an EFL teacher, I tend to value communicative success and risk-taking more highly than correctness. We have decided to voice this difference to the students and make it transparent, rather than adopting a common stance on this, as we feel that both approaches are right for each of their specific contexts.

\subsubsection{Teaching Materials}

The presence of both professors in the same classroom necessarily resulted in a negotiation of teaching materials, whether temporary as in one class together or more permanently in a team-teaching environment.

C3C, PD: Before class we make a decision that we are going to do this first part together without any kind of visual support: This is necessary because I am a teacher who relies a lot on visual support-I use PowerPoints as my lesson plans basically, so I tend to prepare quite extensive PowerPoints with a lot of notes in the notes section. [Prof E] is different: he is a much more holistic teacher who relies less on support materials, so we decide to do this first session his way because we think it's more informal and shows closeness to the students as well as coordination to do it together in the same way.

There are repeated instances of coordination in the creation of teaching materials during the semester between professors.

C5, PB: As agreed with [Prof A] I used the time on Monday to record a video reviewing the main principles of how to write a Lesson plan using our templates. I was really happy that [Prof $\mathrm{A}$ ] watched it right away and volunteered to record Part 2. In this way we ended up sharing with students two 10-minute videos with very practical recommendations and examples in order to help them...

C6, PD: This week [Prof F] uploads a series of short videos on Modernism, for students to watch, and I have a look, too. I really like the way he transmits complex content in a really accessible way and without any visual support at all. ... If I have to resort to online teaching again next year, I'd like to prepare summaries of the main content in this way, too.

Professors adapted each other's materials, created complementary material or aimed to unify their use of materials, to present a coordinated front to students. When there was a lack of materials sharing, instructors also noted this, underlining the importance of sharing in order to know exactly what content was being transmitted in the other's classes.

\subsubsection{Use of Technology}

Instructors often discussed the difference in use of technology, especially after the change to distance learning in March 2020. 


\subsubsection{Differences in Use}

Some professors mentioned feeling comfortable with distance teaching while others said they felt overwhelmed by the change. They also explained some differences in usage, or preferences of usage of technology, among co-teachers.

C2, PB: This, incidentally, is an area of (mild) disagreement between the co-teachers. While [Prof C] believes that we should use all (or most) of the allotted class time [when switching to online classes], I tend to think that 1-h sessions of live seminar, plus all the other tasks, should suffice. This is really not a big issue, as overall I feel that students benefit from the variety of instructional strategies and materials in each co-teacher's module design.

Both professors in one partnership mentioned the same difference of opinion, and both viewed it negatively.

C3B, PE: There is one thing I regret. I should have recorded the sessions as [Prof D] did. I realized too late that in the end it would be more work to meet with the international students if I did not record the sessions.

C3B, PD: One aspect we disagreed on is that I recorded all my class sessions, while [Prof E] did not wish to do that. We just agreed to disagree, but this might be considered an inconsistency in our teaching by the students.

\subsubsection{Transfer of Use of Technological Tools}

There were several instances in the diaries in which professors described learning how to use a technological tool or getting technical assistance from their co-teacher. All of these mentions were positive in nature, pointing to convenience and an efficient use of time.

C7, PG: Working with other teachers is always a help because they share their materials with you, their materials, and knowledge related to everything that has to do with the subject, content, or online tools. On Monday, I had a problem with an online tool and my co-teacher sent me a video with the explanation. I appreciated it a lot due to my lack of time.

C6, PF: During the week, [Prof D] kindly offered to help me create multiple-choice tests on Moodle. [... It It was one clear example of the possible advantages of co-teaching.

\subsubsection{Communication Outside the Classroom}

There was also a need for mutual agreement regarding the use of technology for out-of-class communication and coordination among co-teachers. Channels of communication used by participants in the study were e-mail and the online campus for teacher-student communication, and Whatsapp, phone, email and a shared drive for teacher-teacher communication.

C5, PA: Teacher coordination has generally happened through WhatsApp and emails, and we're generally very communicative to let the other know what we are doing. We share the common calendar and other files as well as the files for each of our modules in Google Drive, which is convenient for both of us.

As seen throughout this reporting of results, comparisons made by participants with respect to their co-teachers were frequent and triggered a learning process involving reflection, negotiation and transfer. This process often affected both instructors' methodology, teaching materials and use of technology.

\section{DISCUSSION}

This section discusses the results of this study, with reference to previous findings on co-teaching, as well as the larger framework for professional development provided by O'Meara and LaPointe Terosky (2010), and the TPACK model of required teacher knowledge (Mishra and Koehler, 2006).

As regards our first research question, the data collected support the view that the type of professional relationships enabled by the different co-teaching arrangements described in this study did indeed drive the co-teachers' respective learning processes. Faculty who participated in the present study continually compared themselves with their co-teachers, always with respect and often admiration for the other instructors. The resulting reflection was an exercise in critical evaluation of their own teaching, whether positive or negative, but usually followed by a plan for action to make improvements. As Lock et al. $(2016,31)$ state, "Co-teaching enhances the fostering of multiple perspectives, encouraging various ways of knowing, as well as nurturing different approaches to teaching".

Furthermore, there is evidence in the diaries that coteaching effectively contributed to the co-teachers' sense of belonging to a team, or being socially embedded (OECD, 2019), while maintaining their autonomy as instructors (Kolleck, 2019). Indeed, comparisons often resulted in a positive evaluation of differences in styles and methodologies-for instance, in relation to the type of feedback given to students-which were generally perceived as valuable to enhancing students' learning outcomes. The diaries also reflect a concern for increased and improved coordination and communication between co-teachers, as well as showing a united front in communication from coteachers to students. Such concerns reveal a commitment to moving from lower to higher levels of faculty collaboration, thus increasing in team entitativity, as understood by Vangrieken et al. (2015). Overall, our findings are consistent with the view that teacher learning and professional relationships are two mutually reinforcing aspects of faculty professional development (O'Meara and LaPointe Terosky, 2010).

Professors' reflections also suggest that the occurrence of such constructive comparisons is by no means automatic, especially in the kind of station teaching contexts described in this paper. Indeed, instructors often admitted to not being 
fully aware of their partner's teaching style, strategies or materials, and insisted on the need of frequent, effective communication between co-teachers, not only to negotiate the choice and application of teaching and assessment materials and instructional methodologies, but to reflect on the teaching process itself (Holland et al., 2018), and incorporate student feedback as necessary (Kelly, 2018). They also highlighted the benefits of agreeing on which specific channels would be employed for out-of-class communication, as recommended by Kelly (2018). On the other hand, faculty expressed the desire to witness their partner in action in order to learn from them, sometimes formulating a plan as to how to achieve this, such as watching a filmed class or planning a shared session. In this respect, the experience of the co-teachers participating in this study suggests that complementing station teaching with occasional team-taught sessions enhances the effect of comparison and, as a result, the instructors' learning processes.

As to the specific learning processes generated by coteaching (RQ2), reflection, negotiation and transfer were the three key strategies that emerged from the co-teachers' diaries. As suggested in previous studies, it appears that co-teaching helped participants become more reflective about their own teaching choices and general style (Bacharach et al., 2008; Ferguson and Wilson, 2011; Kelly, 2018). Furthermore, there are many occasions in which participating faculty described the negotiation of various aspects of the teaching process in order to incorporate both instructors' ideas and find a middle ground (Murphy et al., 2015). In fact, this occurred throughout the semester and through many forms of communication. Finally, participants were frequently ready to describe contributions made by their co-teacher which they liked, added on to, or adopted in their own class sessions, thus building on good practice (Bacharach et al., 2008).

Overall, the three strategies that emerged from our analysis fit well in Laurillard's Conversational Framework (2012, 225) for describing instructors' learning collaboratively about teaching and learning. This model describes the possible effects of conversation about teaching-articulated by words such as explain, comment, critique, defend, propose, and negotiate-on the collaborative instructors' conceptualizations and teaching practice. In Laurillard's own words,

Each teacher uses the practice environment of their learners' learning to achieve the goal of meeting learner needs through generating and modulating their practice and ideas in the light of the feedback from their learners' performance. Working collaboratively with their peers they exchange comments and explanations about their teaching, and share their pedagogical patterns as models of their practice (Laurillard, 2012, 225).

As found in this study, co-teaching, as a strong form of collaborative teaching design, offers extensive opportunities for this form of conversation. Arguably, it also enhances the conversation related to feedback from students, which in many cases is provided to the teaching team as a whole rather than individually.

Finally, the study sheds some light on the value of having the researchers participate in the study as co-teachers. While some form of positive bias must be acknowledged-the belief that coteaching designs are at least worth exploring-we have found that there are positive feedback loops obtained from this dual role. On the one hand, research-minded co-teachers contribute to the conversation with their more professionally oriented peers by promoting "principled-reflective practice" (Laurillard, 2012, 6). From the research perspective, this approach makes research more democratic by resolving the practitioner-examiner dichotomy, developing a more iterative research design (ibid.).

Turning to the third research question of this study, the content of co-teachers' learning bore overwhelmingly on pedagogical and technological knowledge (PK and TK in the TPACK model) with only occasional references being made to reflection on, and discussion of $\mathrm{CK}$. This finding can be largely explained by the fact that the semi-structured template meant to guide the weekly diary entries only touched on discussion of content tangentially, in the context of joint course planning. A second reason for the conspicuous absence of discussion on content knowledge may owe to the extensive use of station teaching, in which instructors naturally specialize in the contents of their respective stations. In such contexts, it is likely that the kind of trust that is often suggested as a precondition for successful co-teaching (Graziano and Navarrete, 2012), and of collaborative teaching in general (Vangrieken et al., 2015), may have contributed to instructors not raising questions about their co-teachers' conceptualizations of the contents to be taught. Previous findings (e.g., Holland et al., 2018) also support the view that transfer of methodology is especially powerful in scenarios in which student-centered methodologies are being pursued, which was the case in the majority of the co-teaching arrangements described in this study.

Regarding the technological knowledge (TK) in the TPACK model, there is a significant amount of reflection on the use of tools, distance-learning methodology and the mutual support between co-teachers when learning to use ICT for teaching. Naturally, the use of technology was highlighted in the diary excerpts above, owing to the change to online and hybrid teaching; thus, this benefit may be more pronounced because of the circumstances of the pandemic. However, it is clear that coteachers support each other when learning to use new tools or applying them to new situations. While no references were found in previous research about contributions of co-teaching to the use of technology, this study suggests that TK may indeed be developed successfully in co-teaching scenarios.

Although co-teaching is positive for faculty and their professional development, there is always room for improving the experience and making it more effective. For example, there are occasions in which conflicts arise, sometimes minor and other times more critical, and instructors would likely benefit from training or guidance in conflict resolution. In fact, Lock et al. (2016) found that the existence of disagreement can be positive when tensions are discussed and negotiated, resulting in a stronger professional 
relationship. It may also be interesting to reflect on which instructors will likely make effective partners based on personal characteristics, professional constraints, goals and stages in their careers and, even, sense of identity in the institution (Smith and Winn, 2017).

As with any research, this paper has been written in a specific context and therefore presents limitations that prevent all conclusions from being extrapolated to other contexts. This innovation project has been carried out in a university in which faculty enjoy significant support from the institution itself, but this may not always be the case. Co-teaching requires support in the form of a collegial leadership style, class schedule adjustments, release time for collaborative planning, connections between departments or programs, and low(er) teacher-student ratios in order to be effective (Graziano and Navarrete, 2012; Ricci and Fingonm, 2017; Kolleck, 2019). Moreover, these conclusions are based on the reflection diaries of a total of seven teacher participants and focus groups held with a total of twenty student participants, from eight course groups across three degrees in just one university. Future studies should include experiences from other disciplines, especially those outside the Social Sciences and Humanities, and other universities, in order to make comparisons. Furthermore, due to time and physical constraints brought on by the COVID-19 pandemic, it was not possible to carry out student focus groups for all the course groups that were included in this study. Therefore, student opinions on the team-teaching experiences (Groups C1 and C2) are not represented, and teacher reflections in the diaries could not be contrasted with student views. Ideally, future studies would contemplate both the teacher and student perspectives in all analyses of co-teaching experiences to paint a more complete picture.

The present study focused on co-teaching partnerships teaching to small student groups, pursuing learner-centered methodologies and, generally, adopting the station teaching model. In future studies, it may also be valuable to compare different models of co-teaching more directly in terms of transfer of methodology and professional development. It is supposed that more direct comparison between instructors occurs when they share the same physical space and in direct proportion to the extent of the communication and sharing of teaching materials between them. Therefore, it could be hypothesized that team teaching situations will result in greater transfer of methodology, though extensive communication and materials sharing also occur in other models. As suggested by the results of this study, an additional line of research would be to explore whether the amount of discussion of teacher knowledge-and content knowledge in particular-reported by coteachers is dependent on variables such as the number of years the teaching partnership has been active or the instruction focus (teacher or learner) which, to some extent, depends on teacher-student ratios. Hypothetically, two co-teachers working together for the first time and lecturing to very large student groups are likely to devote more time to discussing and comparing their respective conceptualizations of the content to be taught. Finally, it would be interesting to explore whether faculty profile-in particular, years of teaching experience and position within the university-affects their perceptions on the extent to which co-teaching contributes to their professional development.
For faculty who embark on this collaborative adventure, coteaching and the comparison between teaching partners it generates necessarily result in profound reflection, negotiation and transfer related to all aspects of the teaching and learning process, and therefore contribute to professional development. Results of the study show that the experience of co-teaching was perceived as clearly beneficial for both students and teachers and therefore it is worthwhile to continue fine-tuning program curricula, recruitment strategies, course syllabi, classroom dynamics and professional development plans in order to make the most of the presence and cooperation of both teachers in the classroom. A significant investment of effort, time, and other resources is involved, but the experience brings about great returns in terms of student achievement and engagement as well as professional development on the part of the co-teachers.

\section{DATA AVAILABILITY STATEMENT}

The datasets presented in this article are not readily available because the consent form used in the study expressly states that "data will only be accessed by members of the project team and for purposes of the project." Requests to access the datasets should be directed to alhernandez@comillas.edu.

\section{ETHICS STATEMENT}

Ethical review and approval was not required for the study on human participants in accordance with the local legislation and institutional requirements. The patients/participants provided their written informed consent to participate in this study.

\section{AUTHOR CONTRIBUTIONS}

$\mathrm{LB}, \mathrm{AL}-\mathrm{H}$ and BS contributed to the design and implementation of the research, to the analysis of the results and to the writing of the manuscript.

\section{FUNDING}

This paper is the result of an internally funded teaching innovation project at Comillas Pontifical University, Madrid, Spain, under the title "Co-teaching as a tool for innovation" (grant number 08-1819).

\section{ACKNOWLEDGMENTS}

This paper is the result of a teaching innovation project comprising five participants. We would like to express our gratitude to Professor Dr. Magdalena Custodio Espinar and Professor Dr. Arturo Peral Santamaría for their contributions to the project. We would further like to 
thank the students and professors who participated in the study for their time and dedication. Last, but not least, we are profoundly grateful for the institutional

\section{REFERENCES}

Bacharach, N., Heck, T. W., and Dahlberg, K. (2008). Co-teaching in Higher Education. Tlc 53, 9-16. doi:10.19030/tlc.v5i3.1298

Bailey, K. M. (1983). "Competitiveness and Anxiety in Adult Second Language Learning: Looking at and through the Diary Studies," in Classroom Oriented Research in Second Language Acquisition. Editors H. W. Seliger and M. H. Long (Rowley, MA: Newbury House), 67-103.

Bailey, K. M. (1990). "The Use of Diary Studies in Teacher Education Programmes," in Second Language Teacher Education. Editors J. Richards and D. Nunan (Cambridge: Cambridge University Press), 215-226.

Baxter, P., and Jack, S. (2008). Qualitative Case Study Methodology: Study Design and Implementation for Novice Researchers. Tqr 13 (4), 544-559. doi:10.46743/ 2160-3715/2008.1573

Blanchard, K. D. (2012). Modeling Lifelong Learning: Collaborative Teaching across Disciplinary Lines. Teach. Theology Religion 15 (4), 338-354. doi:10.1111/j.1467-9647.2012.00826.x

Boud, D. (2001). Using Journal Writing to Enhance Reflective Practice. New Dir. Adult Cont. Educ. 2001, 9-18. doi:10.1002/ace.16

Cabero-Almenara, J., and Llorente-Cejudo, C. (2020). Covid-19: transformación radical de la digitalización en las instituciones universitarias. Campus Virtuales 9 (2), 25-34. Available at: http://www.uajournals.com/ojs/index.php/ campusvirtuales/article/viewFile/713/410

Cameron-Standerford, A., Menard, K., Edge, C., Bergh, B., Shayter, A., Smith, K., et al. (2020). The Phenomenon of Moving to Online/distance Delivery as a Result of COVID-19: Exploring Initial Perceptions of Higher Education Faculty at a Rural Midwestern university. Front. Educ. 5, 583881. doi:10.3389/ feduc. 2020.583881

Carbone, A., Evans, J., Ross, B., Drew, S., Phelan, L., Lindsay, K., et al. (2017). Assessing Distributed Leadership for Learning and Teaching Quality: a MultiInstitutional Study. J. Higher Educ. Pol. Manage. 39 (2), 183-196. doi:10.1080/ 1360080X.2017.1276629

Charmaz, K. (2017). Special Invited Paper: Continuities, Contradictions, and Critical Inquiry In Grounded Theory. Int. J. Qual. Methods 16, 160940691771935-160940691771938. doi:10.1177/1609406917719350

Cook, L., and Friend, M. (1995). Co-teaching: Guidelines for Creating Effective Practices. focusXchild 28 (3), 1-16. doi:10.17161/foec.v28i3.6852

Cowan, J., and Westwood, J. (2006). Collaborative and Reflective Professional Development. Active Learn. Higher Educ. 7 (1), 63-71. doi:10.1177/ 1469787406061149

Custodio-Espinar, M., López Hernández, B., and Buckingham, L. (in press). Effects of Co-teaching on CLIL Teacher Trainees' Collaborative Competence, Profesorado: Revista de currículum y formación del profesorado.

Ellis, R. (2019). "Handbook of Quality Assurance for University Teaching," in Handbook of Quality Assurance for University Teaching. Editors R. Ellis and E. Hogard (London: Routledge), 3-18. doi:10.4324/9781315187518

Ferguson, J., and Wilson, J. (2011). The Co-teaching Professorship: Power and Expertise in the Co-taught Higher Education Classroom. Scholar-Practitioner Q. 5 (1), 52-68. Available at: https://files.eric.ed.gov/fulltext/EJ942564.pdf.

Friedman, D. A. (2012). "How to Collect and Analyze Qualitative Data," in Research Methods in Second Language Acquisition: A Practical Guide. Editors A. Mackey and S. Gass (Boston: Wiley-Blackwell), 180-200. doi:10.1002/9781444347340.ch10

Fuentes Medina, M. E., and Herrero Sánchez, J. R. (1999). Evaluación docente: hacia una fundamentación de la autoevaluación. Revista Electrónica Interuniversitaria de Formación Del. Profesorado 21, 353-368. Available at: http://www.ub.edu/ obipd/wp-content/uploads/2020/03/Dialnet-EvaluacionDocente-2796473.pdf.

Gaebel, M., and Zhang, T. (2018). Trends 2018: Learning and Teaching in the European Higher Education Area. Brussels, Belgium; Geneva, Switzerland: European University Association. Available at: https://www.eua.eu/ downloads/publications/trends-2018-learning-and-teaching-in-the-europeanhigher-education-area.pdf. support received, specifically from the Support Unit for Teaching Innovation and its director, Susana García Martínez.

García-Peñalvo, F. J., and Corell, A. (2020). La COVID-19: ¿enzima de la transformación digital de la docencia o reflejo de una crisis metodológica y competencial en la educación superior? Campus Virtuales 9, 2, 2020 . Available at: http://uajournals.com/ojs/index.php/campusvirtuales/article/view/740.

Graziano, K. J., and Navarrete, L. A. (2012). Co-teaching in a Teacher Education Classroom: Collaboration, Compromise, and Creativity. Issues Teach. Educ. 211, 109-126. Available at: https:/files.eric.ed.gov/fulltext/EJ986819.pdf.

Holland, T., Sherman, S. B., and Harris, S. (2018). Paired Teaching: a Professional Development Model for Adopting Evidence-Based Practices. Coll. Teach. 66 (3), 148-157. doi:10.1080/87567555.2018.1463505

Jasper, M. A. (2005). Using Reflective Writing within Research. J. Res. Nurs. 10 (3), 247-260. doi:10.1177/174498710501000303

Kelly, A. (2018). Co-teaching in Higher Education: Reflections from an Early Career Academic. Jlthe 1 (2), 181-188. doi:10.29311/jlthe.v1i2.2798

Kolleck, N. (2019). Motivational Aspects of Teacher Collaboration. Front. Educ. 4, 122, 2019. article 12. doi:10.3389/feduc.2019.00122

Lasagabaster, D., Doiz, A., and Pavón, V. (2019). Undergraduates' Beliefs about the Role of Language and Team Teaching in EMI Courses at university. Rassegna Italiana di Linguistica Applicata 50 (2-3), 111-127.

Laurillard, D. (2012). Teaching as a Design Science. Building Pedagogical Patterns for Learning and Technology. New York: Routledge. doi:10.4324/ 9780203125083

Lewis, C., and Hurd, J. (2011). Lesson Study Step by Step: How Teacher Learning Communities Improve Instruction. Portsmouth, NH: Heinemann.

Li, Y., Chen, X., Chen, Y., Zhang, F., and Sallam, M. H. (2021). "Investigation of College Teachers' TPACK Level during the Epidemic Situation: Taking Chu Kochen Honors College, Zhejiang University as an Example," in 2021 IEEE 24th International Conference on Computer Supported Cooperative Work in Design (CSCWD), Dalian, China, May 5-7, 2021, 480-484. doi:10.1109/ CSCWD49262.2021.9437867

Lock, J., Clancy, T., Lisella, R., Rosenau, P., Ferreira, C., and Rainsbury, J. (2016). The Lived Experiences of Instructors Co-teaching in Higher Education. Brock Educ. J. 26 (1), 22-35. doi:10.26522/brocked.v26I1.482

Mackey, A., and Gass, S. M. (2016). Second Language Research: Methodology and Design. Oxon/N.Y.: Routledge.

Martínez Vargas, A. E., Cruz Chust, A. M., Bamond Lozano, V. M., Fernández Chaves, I., and Strotmann, B. (2018). La observación formativa como instrumento de desarrollo en profesores universitarios en la Universidad Europea de Madrid. Rev. Complut. Educ. 29 (4), 1365-1380. doi:10.5209/ RCED.55431

Mas Torelló, Ò. (2011). El Profesor Universitario: sus Competencias Y Formación. Profesorado: Revista de Currículum y Formación de Profesorado 153, 195-211.

Mishra, P., and Koehler, M. J. (2006). Technological Pedagogical Content Knowledge: a Framework for Teacher Knowledge. Teach. Coll. Rec. 108 (6), 1017-1054. doi:10.1111/j.1467-9620.2006.00684.x

Montgomery, M. S., and Akerson, A. (2019). Facilitating Collaboration through a Co-teaching Field Experience. Networks: Online J. Teach. Res. 21, 1. doi:10.4148/2470-6353.1284

Morelock, J. R., Lester, M. M., Klopfer, M. D., Jardon, A. M., Mullins, R. D., Nicholas, E. L., et al. (2017). Power, Perceptions, and Relationships: a Model of Co-teaching in Higher Education. Coll. Teach. 65 (4), 182-191. doi:10.1080/87567555.2017.1336610

Murata, A., and Lee, C. (2021). Stepping up Lesson Study: An Educator's Guide to Deeper Learning (London: Routledge). doi:10.4324/9781003002536

Murphy, C., Scantlebury, K., and Milne, C. (2015). Using Vygotsky's Zone of Proximal Development to Propose and Test an Explanatory Model for Conceptualising Coteaching in Pre-service Science Teacher Education. Asia-Pacific J. Teach. Educ. 43 (4), 281-295. doi:10.1080/ 1359866X.2015.1060291

O'Meara, K., and Terosky, A. L. (2010). Engendering Faculty Professional Growth. Change Mag. Higher Learn. 42 (6), 44-51. doi:10.1080/00091383.2010.523408 OECD (2019). TALIS 2018 Results (Volume I): Teachers and School Leaders as Lifelong Learners. Paris: OECD Publishing. doi:10.1787/1d0bc92a-en 
OECD (2020). TALIS 2018 Results (Volume II): Teachers and School Leaders as Valued Professionals. Paris: OECD Publishing. doi:10.1787/19cf08df-en

O'Leary, M., and Savage, S. (2020). Breathing New Life into the Observation of Teaching and Learning in Higher Education: Moving from the Performative to the Informative. Prof. Dev. Educ. 46 (1), 145-159. doi:10.1080/ 19415257.2019.1633386

O’Meara, K., Rivera, M., Kuvaeva, A., and Corrigan, K. (2017). Faculty Learning Matters: Organizational Conditions and Contexts that Shape Faculty Learning. Innov. High Educ. 42, 355-376. doi:10.1007/s10755-017-9389-8

O'Meara, K., Terosky, A. L., and Neumann, A. (2008). Faculty Careers and Work Lives: A Professional Growth Perspective. ASHE Higher Education Report, 34. San Francisco: Jossey-Bass.

Peral Santamaría, A., and Strotmann, B. (2019). "Chapter 6 - El valor añadido de la enseñanza colaborativa bilingüe: un caso práctico," in Bilingual Education under Debate: Practice, Research and Teacher Education. Cáceres: Servicio de publicaciones Universidad de Extremadura.

Pettit, S. L. (2017). Preparing Teaching Candidates for Co-teaching. Delta Kappa Gamma Bullet. 83-3, 15-23. Available at: https://cutt.ly/fpPGbyx.

Phillips, L., and Zavros, A. (2013). "Researchers as Participants, Participants as Researchers," in The Role of Participants in Education Research: Ethics, Epistemologies, and Methods. Editors W. Midgley, P. A. Danaher, and M. Baguley (New York: Routledge), 63-74.

Probst, B. (2016). Both/and: Researcher as Participant in Qualitative Inquiry. Qual. Res. J. 16, 2. doi:10.1108/QRJ-06-2015-0038

Ricci, L. A., and Fingon, J. (2017). Experiences and Perceptions of university Students and General and Special Educator Teacher Preparation Faculty Engaged in Collaboration and Co-teaching Practices. Networks: Online J. Teach. Res. 20, 1-28. doi:10.4148/2470-6353.1260

Ridge, B. L., and Lavigne, A. L. (2020). Improving Instructional Practice through Peer Observation and Feedback: A Review of the Literature. epaa 28, 61. doi:10.14507/epaa.28.5023

Ross, J. A., and Bruce, C. D. (2007). Teacher Self-Assessment: a Mechanism for Facilitating Professional Growth. Teach. Teach. Educ. 23 (2), 146-159. doi:10.1016/j.tate.2006.04.035

Roth, W. M., and Tobin, K. (2004). Coteaching: from Praxis to Theory. Teach. Teach. 10 (2), 161-179. doi:10.1080/0954025032000188017

Saldaña, J. (2021). The Coding Manual for Qualitative Researchers. London/ Thousand Oaks/New Delhi/Singapore: Sage.

Schwab, S., Holzinger, A., Krammer, M., Gebhardt, M., and Hessels, M. G. P. (2015). Teaching Practices and Beliefs about Inclusion of General and Special Needs Teachers in Austria. Learn. Disabilities: A Contemp. J. 13 (2), 237-254.

Simons, M., Baeten, M., and Vanhees, C. (2020). Team Teaching during Field Experiences in Teacher Education: Investigating Student Teachers' Experiences with Parallel and Sequential Teaching. J. Teach. Educ. 71 (1), 24-40. doi: $10.1177 / 0022487118789064$

Smith, K. K., and Winn, V. G. (2017). Co-teaching in the College Classroom. Teach. Educ. 28 (4), 435-448. doi:10.1080/10476210.2017.1325863

Strotmann, B., and Custodio Espinar, M. (2021). "La codocencia reflexiva en la educación superior - [Reflective co-teaching in higher education]," in Innovaciones docentes en tiempos de pandemia: Actas del VI congreso internacional sobre aprendizaje, innovación y cooperación, CINAIC 2021. Editors M. L. Sein-Echaluce Lacleta, A. Fidalgo Blanco, and F. J. García Peñalvo (Zaragoza: Publicaciones Universidad de Zaragoza), 216-221. doi:10.26754/CINAIC.2021.0043

Stynes, M., Murphy, T., McNamara, G., and O'Hara, J. (2018). Reflection-onaction in Qualitative Research: a Critical Self-Appraisal Rubric for Deconstructing Research. Issues Educ. Res. 281, 153-167. Available at: http://www.iier.org.au/iier28/stynes.pdf.

Torra Bitlloch, I., de Corral Manuel de Villena, I., Pérez Cabrera, M. J., Pagès Costas, T., Valderrama Valles, E., Màrquez Cebrian, M. D., et al. (2012). Identificación de competencias docentes que orienten el desarrollo de planes de formación dirigidos a profesorado universitario. Redu 10 (2), 21-56. doi:10.4995/redu.2012.6096

Turan, M., and Bayar, B. (2017). Examining Teachers View on Primary Teaching Practices Based on Co-teaching Model. Jets 5 (11), 82-97. doi:10.11114/ jets.v5i11.2708

Vangrieken, K., Dochy, F., Raes, E., and Kyndt, E. (2015). Teacher Collaboration: A Systematic Review. Educ. Res. Rev. 15, 17-40. doi:10.1016/ j.edurev.2015.04.002

Conflict of Interest: The authors declare that the research was conducted in the absence of any commercial or financial relationships that could be construed as a potential conflict of interest.

Publisher's Note: All claims expressed in this article are solely those of the authors and do not necessarily represent those of their affiliated organizations, or those of the publisher, the editors and the reviewers. Any product that may be evaluated in this article, or claim that may be made by its manufacturer, is not guaranteed or endorsed by the publisher.

Copyright $\odot 2021$ Buckingham, López-Hernández and Strotmann. This is an openaccess article distributed under the terms of the Creative Commons Attribution License (CC BY). The use, distribution or reproduction in other forums is permitted, provided the original author(s) and the copyright owner(s) are credited and that the original publication in this journal is cited, in accordance with accepted academic practice. No use, distribution or reproduction is permitted which does not comply with these terms. 